\title{
A educação de pessoas privadas de liberdade numa perspectiva inclusiva e ressocializadora: limites e contradições
}

\author{
DUARTE, Ana Maria Tavares ${ }^{1}$ \\ PEREIRA, Cleyton Feitosa ${ }^{2}$
}

\section{Resumo}

Este trabalho se propõe tecer reflexões teóricas sobre a educação no contexto de privação de liberdade, dando visibilidade para uma temática a ser enfrentada pelos educadores na academia. A educação das pessoas em situação de privação da liberdade enfrenta inúmeros desafios quer no âmbito político, quer no âmbito pedagógico. No âmbito político verifica-se as contradições voltadas para o conflito existente sobre a finalidade da educação do apenado, se serve promover a socialização ou a redução penal. No âmbito pedagógico, os desafios perpassam principalmente o nível da qualidade e da função educativa dentro do sistema penitenciário. Uma realidade tipicamente não-formal como é a prisão na maioria das vezes, possui como modelo educativo a reprodução de uma educação formal. A prisão e as unidades de cumprimento de medidas socioeducativas, são caracterizadas pela superpopulação, práticas continuadas de tortura contra os internos (as), espaço de descumprimento da legislação nacional e internacional de garantia dos direitos dos apenados (as) e de adolescentes em conflitos com a lei, espaços esses dominados pelo crime, pela promiscuidade de valores, de corrupção entre internos, agentes do Estado e demais elementos que compõem as relações nesses espaços. Frente a esses problemas identificou-se a urgência na adequação curricular com ênfase na reformulação e na formação inicial e em serviço dos professores. As instituições de ensino superior devem desenvolver um currículo que contemple satisfatoriamente discussões teóricas e práticas no âmbito de atuação no campo de estágios, bem como na sistematização de disciplinas voltadas às questões didático-pedagógicas que possibilitem refletir sobre a atuação docente neste contexto. A emergência de uma proposta curricular eficaz que atenda às necessidades educativas da pessoa privada de liberdade, contextualizada a sua realidade sociocultural, deve partir do pressuposto da existência de uma cultura carcerária que necessita ser considerada. $O$ trabalho apresentou críticas epistêmicas às instituições de ensino superior que invisibilizam através de suas ações acadêmicas, realidades educativas semelhantes às do presídio. Os sistemas de ensino são desafiados a desenvolver articulações que rompam com a cultura de violência, e passem a se fundamentar numa educação em direitos humanos, a ser discutida e viabilizada dentro das unidades prisionais. Pontua-se que já existem algumas publicações de autores/as brasileiros/as que discutem a importância da educação prisional na modalidade EJA numa dimensão voltada à legitimação dos Direitos Humanos de detentos e as representações docentes neste campo educativo.

Educação Prisional. Direitos humanos. Formação de educadores.

\footnotetext{
${ }^{1}$ Professora Dr. ․ na Universidade Federal de Pernambuco -CAA, Líder do Grupo de Pesquisa: Educação, Inclusão social e Direitos Humanos e vice coordenadora da Licenciatura Intercultural Indígena. E-mail: familliaduarte@uol.com

2 Doutorando em Ciência Política pela Universidade de Brasília - UnB. Mestre em Direitos Humanos pela Universidade Federal de Pernambuco - PPGDH/UFPE. Licenciado em Pedagogia pela Universidade Federal de Pernambuco - CAA. E-mail: cleyton_feitosa@hotmail.com
} 


\section{Resumen}

Este artículo se propone a tejer reflexiones teóricas acerca de la educación en el contexto de privación de libertad, dando visibilidad para una temática a ser enfrentada por los educadores en la academia. La educación de las personas en situación de privación de libertad enfrenta inmensos desafíos, sea en ámbito político, o en ámbito pedagógico. En el ámbito político, verificase las contradicciones vueltas para el conflicto existente acerca de la finalidad de la educación del encarcelado, se sirve para promover la socialización o la reducción penal. En el ámbito pedagógico, los desafíos pasan principalmente por el nivel de la calidad e de la función educativa dentro del sistema penitenciario. Una realidad típicamente no formal como es la prisión en la mayoría de las veces, posee como modelo educativo, la reproducción de una educación formal. La prisión y las unidades de medidas socioeducativas, son caracterizadas por la superpoblación, prácticas continuadas de tortura contra los internos(as), espacio de incumplimiento de la legislación nacional e internacional de garantía de los derechos de los encarcelados, así como los adolescentes en conflicto con la ley, espacios eses que son dominados por el crimen, promiscuidad de valores, de corrupción entre internos, agentes del Estado y muchos más elementos que componen las relaciones en eses espacios. Delante eses problemas, se ha identificado la urgencia en la adecuación curricular con énfasis en la reformulación y en la formación inicial y en servicio de los profesores. Las instituciones de enseñanza superior deben desarrollar un currículo que contemple satisfactoriamente discusiones teóricas y prácticas en el ámbito de actuación de lo campo de prácticas obligatorios, bien como en la sistematización de las disciplinas vueltas a cuestiones didáticopedagógicas que posibiliten reflejar acerca de la actuación docente en ese contexto. La emergencia de una propuesta curricular eficaz que atienda a las necesidades educativas de la persona privada de libertad, contextualizada a su realidad sociocultural, debe partir del presupuesto de la existencia de una cultura carcelaria que necesita ser considerada. Este artículo ha presentado críticas epistémicas a las instituciones de enseñanza superior que invisibilizan a través de sus acciones académicas, realidades educativas semejantes as de lo presidio. Los sistemas de enseñanza son desafiados a desarrollar articulaciones que rompan con la cultura de violencia, y pasen a fundamentarse en una educación de derechos humanos, que debe ser discutida y viabilizada dentro de las unidades prisionais. Se puntúa que ya existen algunas publicaciones de autores(as) brasileños(as) que discuten la importancia de la educación prisional en la modalidad EJA en una dimensión vuelta a la legitimación de los Derechos Humanos de detenidos y las representaciones docentes en este campo educativo.

\section{Educación prisional. Derechos Humanos. Formación de educadores.}

\section{Introdução}

O debate em pauta sobre a educação no contexto de privação de liberdade enfrenta inúmeros desafios quer no âmbito político, quer no âmbito pedagógico. Suas razões atingem as esferas que perpassam principalmente o nível da qualidade e da função educativa deste processo, numa realidade tipicamente não formal como é a prisão que na maioria das vezes possui como modelo educativo a reprodução de uma educação formal, neste cenário, extremamente descontextualizado à realidade do sujeito do processo educativo 
em questão, a saber, a pessoa privada de liberdade está sob a tutela do Estado.

O Sistema Penitenciário Brasileiro é espaço de inúmeros conflitos, a superpopulação é apenas a ponta do iceberg que demonstra a insuficiência de vagas e o aumento de detentos como resultado do crescimento da criminalidade e da violência em escala nacional e internacional. Tal fato provoca um aumento significativo da população carcerária que contribui para a superlotação das unidades causando imensos desafios para as gestões de presídios e penitenciárias, que convivem com esta realidade pouco animadora, principalmente por inviabilizar ações voltadas à implantação de processos educativos que visem a ressocialização de detentos.

\section{A prisão e a negação do estado de direito no Brasil}

Em 1985, do ponto de vista política e em 1988 do ponto de vista jurídico se encerrava a ditadura militar no Brasil, a eleição indireta de Tancredo Neves e a nova constituição restauraram o Estado de direito no Brasil. No entanto, a forma como se deu o processo de anistia que manteve no aparelho de segurança do estado brasileiro figuras ligadas à tortura, às atrocidades que foram cometidas durante o regime de exceção, permitiu que essas condutas, mesmo dentro do processo democrático, continuassem sendo vivenciadas pelos prisioneiros comuns.

A prisão brasileira: Penitenciárias, presídios, cadeias públicas e sem excluir as unidades de cumprimento de medidas sócio - educativas, que pouco se distinguem das prisões, são espaços da continuidade da prática das mais variadas violações de direitos humanos, cometidas contra: Homens, mulheres e adolescentes em conflito com a lei.

A prisão e as unidades de cumprimento de medidas sócio educativas, são caracterizadas pela superpopulação, práticas continuadas de tortura contra os internos(as), espaço de descumprimento da legislação nacional e internacional de garantia dos direitos dos apenados/as e de adolescentes em conflitos com a lei. Espaços dominados pelo crime, pela promiscuidade de valores, de corrupção entre internos, agentes do Estado e demais elementos que compõem as relações nesses espaços.

Propomos discutir sobre a emergência de uma proposta curricular eficaz que atenda às necessidades educativas da pessoa privada de liberdade, contextualizada a sua realidade sociocultural, partindo do pressuposto da existência de uma cultura carcerária que necessita ser considerada para a elaboração desta proposta.

Frente a este emblema nos deparamos ainda com a formação inicial de professores que em grande parte das grades curriculares de cursos voltados a formação de professores, não apresenta satisfatoriamente discussões teóricas e práticas tanto no âmbito de atuação no campo de estágios, como na sistematização de disciplinas voltadas ao campo didático-pedagógica que 
possibilite refletir sobre a atuação docente neste contexto. Sendo assim, realizamos apontamentos que fazem alusão à formação docente inicial e continuada no contexto de privação de liberdade.

Por fim, apresentamos críticas epistêmicas às instituições de ensino superior que invisibilizam através de suas ações acadêmicas, realidades educativas semelhantes como o presídio, salvo algumas instituições de ensino superior brasileiras, que desenvolvem trabalhos, que podemos dizer, são de resistência, frente aos entraves principalmente de financiamento e de interesse da sociedade de um modo geral. Embora em número menor, existem publicações de autores/as brasileiros/as que discutem a importância da educação, modalidade EJA para o presídio, principalmente numa dimensão voltada à legitimação dos Direitos Humanos de detentos e as representações docentes neste campo educativo restringindo, portanto, um debate pertinente para a Ciência da Educação e utilizado como quadro teórico nesta reflexão acadêmica.

2 Questões emergentes: A educação prisional como direito, formação de professores/as e proposta curricular

A educação, segundo a Constituição Federativa da República do Brasil de 1988 é um direito fundamental, e o seu ensino gratuito é direito público subjetivo.

Art. 205. A educação, direito de todos e dever do Estado e da família, será promovida e incentivada com a colaboração da sociedade, visando ao pleno desenvolvimento da pessoa, seu preparo para o exercício da cidadania e sua qualificação para o trabalho. (BRASIL, 1988).

Embora contraditório o que deveria ser um direito, em alguns espaços da sociedade, a educação brasileira não vem atendendo satisfatoriamente a necessidade do povo. Frente ao número de brasileiros que não avançam no nível de escolarização devido à ausência de escolas suficientes e por não atenderem às necessidades dos alunos, devido ao modelo em que historicamente fora criado: para atender as necessidades de uma classe social privilegiada.

Sabe-se, que nos últimos anos as políticas sociais voltadas à educação, vêm se ampliando e avançando para sujeitos educativos oriundos da realidade campesina, periferia das grandes cidades através de processos de alfabetização e elevação da escolaridade na medida em que tem acesso a uma escola formal. Na perspectiva da Educação de Jovens e Adultos, temos o projeto Brasil Alfabetizado, por exemplo. (GOMES e CÂMARA, 2010).

Neste contexto a nossa Constituição Federal de 1988, assim como a Lei de Diretrizes e Bases da Educação Nacional (LDBEN) de 1996, asseguram 
e reforçam o direito à educação como um dos princípios legais que legitima a cidadania do brasileiro (OLIVEIRA, 1999). Tratando-se de documentos e tratados legais internacionais a Declaração dos Direitos Humanos da ONU, promulgada em 1948, referenciam a educação como importante para o reconhecimento e emancipação cidadã do homem, no sentido em que devem ser incentivadas as atividades culturais e intelectuais para 0 seu desenvolvimento, assim como trata o artigo 26 da mesma.

Art. 26. 1. Toda a pessoa tem direito à educação. A educação deve ser gratuita, pelo menos a correspondente ao ensino elementar fundamental. $\mathrm{O}$ ensino elementar é obrigatório. $\mathrm{O}$ ensino técnico e profissional dever ser generalizado; o acesso aos estudos superiores deve estar aberto a todos em plena igualdade, em função do seu mérito.

2. A educação deve visar à plena expansão da personalidade humana e ao reforço dos direitos do homem e das liberdades fundamentais e deve favorecer a compreensão a tolerância e a amizade entre todas as nações e todos os grupos raciais ou religiosos, bem como o desenvolvimento das atividades das Nações Unidas para a manutenção da paz.

3. Aos pais pertence a prioridade do direito de escolher 0 gênero de educação a dar aos filhos.

O discurso dos direitos humanos é uma questão, sobretudo de cunho educativo, portanto, inerente às discussões que se pautam sobre educação. Outras ciências se apropriam desta discussão, a saber, Ciência Política, Sociologia além do Direito compreendendo que numa globalidade epistemológica perpassa diversos segmentos que buscam estudar, compreender e interferir na realidade concreta, caminhando a implantação de princípios e de uma sociedade democrática e de direito, justa e igualitária.

Os cenários de violação dos direitos humanos a qual segundo Matteuci (1992) dividem-se em Direitos civis, Direitos Políticos e Direitos Sociais são muitos e variados. A educação se enquadra nos Direitos sociais, que além dela são direitos: trabalho, assistência social, saúde, previdência e lazer (GOMES e CÂMARA, 2010). Estes, tidos como direitos fundamentais ao homem, dentre outros.

Refletir sobre o direito à educação, principalmente em um modelo estatal pautado em diretrizes políticas associadas ao sistema neoliberal nos é desafiante, na medida em que consideramos que a política enquadrada neste novo modelo de sociedade é de desresponsabilização do Estado frente à economia, que atinge também a esfera social.

Segundo este modelo, as políticas sociais adquirem caráter compensatório, como um meio de desestabilizar setores da organização civil no que concerne à luta pelos seus direitos constitucionais e legitimação de sua 
cidadania. Diante deste entrave, tais bandeiras de lutas atingem a esfera do reconhecimento dos direitos humanos que ao longo da história, segundo Soares (2004), adquire três dimensões:

\begin{abstract}
As três dimensões históricas dos direitos humanos - as quais se confundem, de certa forma, com as etapas históricas da cidadania, engloba e enfeixa os três ideais da Revolução Francesa: o da liberdade, o da igualdade e o da fraternidade, ou da solidariedade. Além de naturais, universais e históricos, os direitos humanos são também, indivisíveis e interdependentes. São indivisíveis e interdependentes porque à medida que são acrescentados ao rol dos direitos fundamentais da pessoa humana não podem mais ser fracionados. (SOARES, 2004, p. 64).
\end{abstract}

A educação da pessoa privada de liberdade é um direito assegurado pela Lei de Execução Penal - LEP (1984) e padece de um conflito existencial em relação aos entraves políticos e sociais pelo qual se pautam as discussões relacionadas ao sistema penitenciário brasileiro, como o da privatização das unidades prisionais e o desinteresse da sociedade que invisibiliza esta questão, por se tratar de uma abordagem indesejada: o direito do preso (PORTUGUÊS, 2001), (BARROS e JORDÃO, 2004), (BARROS, 2009). Este, de fato excluído da dinâmica social, por não ter atendido e obedecido às regras e normas instauradas para todo e qualquer modelo de sociedade, que regula, controla e estabelece as relações de poder e divisão de classes nela existentes.

A educação, que deveras é garantida por documentos legais, enfrenta diversos desafios tanto na sua implantação, considerando que uma escola no contexto prisional requer uma estrutura física adequada para que se concretize o ato educativo, formação de professores para atuar nesta realidade, continuidade dos processos educativos, este apontado como um dos maiores entraves (BARROS, 2009) devido o processo migratório e dinâmico pelo qual o aluno aprisionado se submete e amparado pela lei penal, como troca de penitenciária, saída do regime fechado para o aberto ou semiaberto e até mesmo quando reincide no crime, retornando, assim, ao presídio. Outro desafio é a eficácia do processo educativo no contexto prisional que visa à alfabetização, elevação da escolaridade, profissionalização e oportunidades de acesso ao emprego, que em sua matriz curricular, inexistente para esta realidade, não infere nenhuma adaptação curricular nem o desenvolvimento de um projeto de currículo específico para este contexto. Algo que já vem acontecendo em outras realidades, como um currículo específico para as escolas rurais a título de exemplo.

Neste sentido, a educação, que segundo o dispositivo legal citado (LEP, 1984) em seção específica que trata da assistência educacional, a seção V nos aponta que: 
Art. 17 A assistência educacional compreenderá a instrução escolar e a formação profissional do preso e do internado.

Art. 18. O ensino de primeiro grau será obrigatório, integrandose no sistema escolar da unidade federativa.

Art. 19. O ensino profissional será ministrado em nível de iniciação ou de aperfeiçoamento técnico.

Parágrafo único - A mulher condenada terá ensino profissional adequado à sua condição.

Art. 20. As atividades educacionais podem ser objeto de convênio com entidades públicas ou particulares, que instalem escolas ou ofereçam cursos especializados.

Art. 21. Em atendimento às condições locais, dotar-se-á cada estabelecimento de uma biblioteca, para uso de todas as categorias de reclusos, provido de livros instrutivos, recreativos e didáticos. (BRASIL, 1984).

Uma breve análise do texto legal, já nos aponta as contradições aos quais o apenado padece frente aos direitos que the são fundamentais, o acesso à educação, esta abordagem que trata este ensaio, lhe tem como violações. Pois, o Estado ainda não consegue dialogar com esta realidade e especificidade pelo qual o nosso sistema penitenciário está inserido (BARROS e JORDÃO, 2004) e que por sua vez, não comporta uma legítima educação prisional que favoreça a emancipação dos sujeitos educativos, oportunizando a cidadania do preso.

Destacamos o pensamento de Barros e Jordão (2004) sobre as violações de direitos humanos, principalmente no Brasil, quando afirmam "Entendemos que o problema relativo às violações dos direitos dos presidiários no Brasil se relaciona à fragilidade do nosso Estado de Direito, o que permite que em nosso país a prática da violência contra os direitos humanos ocorram com tanta frequência e "naturalidade" (p.11). De fato, concordamos com as autoras ao perceber que a realidade concreta das nossas unidades prisionais não atende as especificidades de um espaço educativo adequado à formação humana ressocializadora e inclusiva, devido entre outras questões, à superlotação das unidades contribuindo, portanto, a violação dos direitos humanos.

A arquitetura dos presídios (FOUCAULT, 1987), por exemplo, não foram elaboradas para que os reclusos pudessem reaprender 0 exercício da cidadania humana através da educação, do trabalho e da arte. Estas, fundamentais para o desenvolvimento humano e importantes para o trabalho de inclusão dos presos na sociedade a qual terá de acolhê-lo após o cumprimento de sua pena, que por sua vez, poderá desencadear em um processo de ressocialização do apenado. Mas sim para a vigilância e controle dos mesmos. 
A escola na prisão não atende os princípios democráticos, funciona muito mais como complemento de docilização do detento, um instrumento complementar de segurança do que em uma proposta pedagógica concreta de formação de valores. As salas de aulas são espaços de contenção de pessoas em sua maioria são ações isoladas de Instituições de Ensino Superior que atuam nesta realidade com os discentes em formação, principalmente no âmbito da carga horária de estágio. Há um sentimento de rejeição a pessoa humana do detento e um desejo neonazista para que desapareçam do espaço social, independente das condições em que sejam submetidos: violência, extermínio ou superlotação prisional.

A realidade prisional Pernambucana, em suas unidades prisionais, apresenta um modelo de escola tipicamente formal, pois as mesmas estão subordinadas a unidades escolares próximas ao bairro em que são alocadas as penitenciárias (SILVA, 2006). Seguindo o regimento, planejamento, avaliação e calendário escolar imposto pela gestão escolar, que por vezes, em nada condiz com o processo educativo pelo qual o preso necessita.

Estas escolas desenvolvidas para atender a uma exigência legal, foram pensadas num modelo de escola formal. Mas, basta uma visita a um presídio, e por sua vez, a uma sala de aula nesta realidade educativa para compreendermos que não se trata de uma escola tipicamente formal. $E$ assim qualquer iniciativa de processo educativo nesses espaços, embora forçosamente louváveis, terão pouco êxito. É importante ressaltar que os saberes trazidos pelos educandos, nesta realidade educativa são variados e diversos, que por sua vez, deverão ser considerados relevantes durante o processo educativo, de ensino e aprendizado (SILVA, 2006).

O perfil do apenado brasileiro é o de sujeito pobre e sem perspectivas de vida. $O$ crime e a marginalidade lhe foram às únicas alternativas apresentadas por um modelo de sociedade embasada em princípios capitalistas. Este modelo de Estado legitima a punição, a criminalidade e marginalidade. A mídia, formadora de opinião, contribui no modo de pensar de nossa sociedade ao difundir ideias e princípios que ferem o reconhecimento e a legitimação dos direitos humanos de detentos. Sabe-se, portanto, que é importante para aqueles que detêm o poder em nosso modelo de sociedade, controlar a opinião pública, e são através dos canais de comunicação mais diversos que esta ação se concretiza e se reproduz.

Neste sentido, refletir sobre os desafios postos a esta realidade educativa parece-nos tarefa árdua, se considerar dois entraves, dentre tantos outros que perpassa o cenário educativo em pauta, o primeiro é a formação de professores na perspectiva da inclusão do detento, e por último uma proposta curricular clara que atenda às necessidades educacionais neste contexto socioeducativo. 
Costa e Farias (2009) refletem sobre a necessidade de uma formação continuada ou "em serviço" como reforça as autoras, frente aos entraves pelos quais muitos dos profissionais da educação enfrentam no cotidiano da prática docente. Acrescenta que, muitas destas formações não adquirem significados, por geralmente, não atenderam as necessidades reais dos professores. Uma vez que estas formações são pensadas por grupos gestores que atuam descontextualizados das realidades educativas. Embora as autoras não pontuem a problemática da formação de professores que atuam em contextos prisionais, o pensamento de ambas nos possibilita refletir acerca dos profissionais que atuam no contexto prisional, que frequentam espaços de formação continuada para professores que atuam de um modo geral, em escolas tipicamente formais.

Se os profissionais da escola regular formal não se sentem contempladas nas formações específicas, diga-se como, deverão sentir-se os professores de escolas alocadas em penitenciárias, que necessitam conviver com a baixa estima de alunos (BARROS, 2009) que frequentam a modalidade da educação de jovens e adultos e os déficits de aprendizagem destes, frente aos modelos de planejamento escolar que não atende a esta realidade educativa em específico?

Torna-se, portanto, emergente a discussão sobre a elaboração de uma proposta curricular que atenda esta realidade. É preciso que haja um debate acadêmico, mas também político que objetive em experiências de atuação docente, buscando sistematizá-las, no intuito de elaborar um conhecimento necessário para os processos de docência, subsidiado em bases legais, assegurando o direito à educação prisional, que já é vista como uma possibilidade de remissão de pena, mas também como uma nova oportunidade de elevação da escolaridade, por meio de processos desenvolvidos em salas de EJA. A ausência de um currículo específico para a realidade prisional é um entrave significativo para o fracasso da educação prisional.

\section{A invisibilidade da educação de pessoas privadas de liberdade nas instituições de ensino superior no Brasil}

Uma universidade está em uma região tão-somente para desenvolver suas potencialidades: econômica, cultural, social, tecnológica e científica, intervindo desta maneira para uma melhoria nas condições de vida das pessoas. Diante de tantas responsabilidades, pode-se ver as diversas áreas de atuação e de conhecimento que ela contempla e abrange: educação, saúde, engenharias, tecnologias, jurídico, biologia, epistemologia, entre outras. As ciências são tratadas e estudadas com fins de ampliação e produção de novos saberes. 
No entanto, a educação penitenciária em sua totalidade não contém essa parcela de atenção que a academia presta às diversas áreas do conhecimento, o que prejudica seriamente a construção de uma sociedade mais democrática e justa. Não fosse alguns/as intelectuais que se debruçam sobre esta temática no sentido de compreendê-la e melhorá-la, essa questão continuaria omissa e negligenciada por parte do ensino superior público e privado numa perspectiva de inclusão social. A discussão sobre pena e prisão ficaria limitada aos debates jurídico-legais que determinam a situação do aprisionado. Contudo, os saberes educativos, as quais os/as licenciados possuem, precisam fazer parte desta discussão, na direção da ressocialização do detento e no desenvolvimento justo e pacífico de nossa nação.

Se a academia discute a natureza e as consequências de um sistema político-econômico neoliberal, esta deve também pautar pelas questões da educação penitenciária: sua organização, currículo, administração, execução, avaliação, planejamento e todo o bojo que as teorias educativas refletem e discutem.

A falta de discussão desta temática no espaço acadêmico recai sobre as produções e publicações em grandes revistas científicas consideradas importantes no que tange ao panorama teórico contemporâneo. Esta afirmação é constatada por Lucena (2010) ao escrever:

\begin{abstract}
A realização de um levantamento bibliográfico no site da CAPES e em periódicos da educação (Revista Brasileira de Educação e Revista Educação \& Pesquisa, anos 2005, 2006 e 2007) permitiu identificar que as produções acadêmicas existentes na área da educação sobre as pessoas encarceradas, mais especificamente, as mulheres, quase inexistem. Das poucas teses e dissertações encontradas, vimos que é muito pouca a visibilidade dada às experiências de vida e de aprendizagens das mulheres que chegam às prisões e aos significados por elas produzidos acerca das experiências vividas nestes contextos. As discussões nestes trabalhos se voltam mais aos problemas de ordem estrutural e pedagógica dos presídios, os quais emperram o processo educativo e menos às experiências concretas dos sujeitos nesses contextos inseridos. (LUCENA, 2010, p. 2).
\end{abstract}

Com efeito, é pouca a produção de escritos sobre tal tema, sobretudo se compararmos a outras áreas da educação que já estão bastante exploradas, consideradas, inclusive, tradicionais. É curioso observar neste trecho a relação de gênero posta na afirmação: se já é dificultoso encontrar trabalhos sobre o preso homem, imaginemos a presidiária mulher, o que representa ainda resquícios de uma sociedade machista, que vê no homem o protagonista e na mulher mera coadjuvante. 
No caso do Centro Acadêmico do Agreste da Universidade Federal de Pernambuco, licenciatura em Pedagogia, o currículo do curso apresenta uma disciplina intitulada "Educação Penitenciária e Ressocialização de Detentos" que vem trabalhando numa perspectiva científica, prática e humana da questão prisional brasileira. Esta é uma componente curricular eletiva, não sendo de caráter obrigatório, ou seja, somente as pessoas interessadas a conhecer e discutir o tema é quem cursa esta disciplina. Sendo uma disciplina eletiva do currículo do curso, esse debate também poderia estar contido na educação e direitos humanos que também é eletiva, sendo a outra possibilidade de que alguns grupos de alunos se interessassem pelo tema. A transformação desse componente eletivo em obrigatório possibilitaria que na formação dos professores esta discussão viesse a ser contemplada.

Neste sentido, reportamo-nos ao pensamento de Gramsci, amparado por Mari (estudioso da contribuição gramsciana), quando o teórico italiano fala da função da universidade enquanto instituição autônoma, crítica e fundamental para uma transformação social.

A função das universidades, no conjunto do pensamento gramsciano (1989, p. 125), também vai no sentido de reforçar uma consciência homogênea e autônoma, educar os cérebros para pensar de modo claro, libertando-os de uma cosmovisão caótica, corroborada por uma cultura inorgânica, pretensiosa e confusa. (...) para nós, do Brasil, a função da universidade enquanto espaço de elevação da cultura, de superação do "senso comum" e de formação dos cidadãos capazes de uma compreensão homogênea das várias dimensões da sociedade. (MARI, 2003, p. 8 - 9).

De fato, a universidade se trata de uma instituição autônoma e que deve fomentar autonomia aos seus usuários no sentido de desenvolver a sociedade: e a ressocialização do/a detento/a é questão fundamental no que diz respeito a uma sociedade harmônica e democrática. A educação penitenciária, aliada a outras discussões como a jurídica, sociológica, psicológica, entre outras, é prérequisito básico para a formação de novos sujeitos. Sujeitos estes que violaram a lei, tiveram sua liberdade tolhida e retornarão à sociedade posteriormente. 0 retorno à rotina comum implica numa formação ressocializadora humana e cidadã que prime pela melhoria do sujeito aprisionado e da sociedade a qual todos fazemos parte. A academia não pode negligenciar tal questão. A esse respeito Barros analisa.

Apesar de todas as características que envolvem a educação penitenciária, o Estado brasileiro e as universidades não despertaram ainda para a sua importância no momento histórico em que vivemos, as prisões brasileiras se encontram abarrotadas de jovens que se encontram com Estado, muitas vezes, pela primeira vez na prisão. A escola, por exemplo, 
muitos só a frequentam na prisão. Essa razão por si, já deveria despertar uma ampla preocupação com a qualidade do ensino e a função social da educação na prisão, mas também, pelo fato de que a Educação Penitenciária é motivo de remissão ${ }^{3}$ da pena do prisioneiro. No Estado de Pernambuco, essa remissão depende da aprovação do detento naquela série em que está matriculado. Razão pela qual a educação no cárcere necessita de um pensamento pedagógico próprio que pense seus aspectos éticos, políticos e metodológicos, possibilitando ao educador uma formação continuada para que não se sinta inferiorizado e sem saídas e que o articulem aos debates em educação especial, na medida em que a prisão ainda é um espaço quase desconhecido pela ciência da educação. (BARROS, 2009, p. 117).

Não fosse a disposição de alguns intelectuais orgânicos ${ }^{4}$ em debater tal questão, a educação penitenciária continuaria desprezada e invisibilizada nas universidades. Para Mari (2003):

Os intelectuais possuem uma função orgânica bastante importante no processo da reprodução social, na medida em que ocupam espaços sociais de decisão prática e teórica, tornando-os objeto de longa análise nos Cadernos do Cárcere ${ }^{5}$. Mas a principal função destes se encontra na formação de uma nova moral e uma nova cultura, que podem ser entendidas também como uma contra hegemonia, já que o objetivo final das lutas organizativas seria, no seu momento histórico, 0 socialismo. (MARI, 2003, p. 1-2).

Todavia, a universidade não deve prescindir de pessoas que estejam dispostas a discutir a questão, devendo ter em seu arcabouço teórico, metodológico e prático uma preocupação e comprometimento que estimule a formação de novos/as intelectuais orgânicos no sentido de tratar a questão de maneira fundamental com vistas ao desenvolvimento justo e democrático da sociedade brasileira, ou seja, criando linhas de pesquisa, inserindo no currículo dos cursos o tema, desenvolvendo projetos de extensão e formando profissionais da educação (e de outras áreas do conhecimento) para lidar com tal fenômeno em sua amplitude: escolar, não-escolar, cidadã, humana, crítica e popular.

\footnotetext{
${ }^{3}$ Redução da pena através do trabalho e do estudo. Ex. Três dias de estudo, reduz um dia da pena. 4 Tomamos por intelectual orgânico a contribuição de Gramsci a qual afirma que este tipo de intelectual é aquele/a que vai além do pensamento meramente teórico e da estagnação social, criando, assim, uma filosofia da práxis. Pertence a uma classe ou grupo social, credibilizando assim seu modo de produção e suas relações econômicas, sociais e políticas. Trata-se também do/a intelectual que, tomando consciência da economia, sociedade e política dominante e hegemônica analisa e milita numa perspectiva contra hegemônica no sentido de democratizar as relações e a sociedade (SEMERARO, 2006).

${ }^{5}$ Principal obra gramsciana, escrita entre 1929 e 1937. Contém o núcleo central de todos as grandes reflexões do autor.
} 


\section{Os educadores na prisão e a cultura carcerária}

A inexistência de um Estado de direito no Brasil, somado as características do confinamento, criaram uma cultura carcerária no Brasil marcada pela violência. Se por um lado, a manutenção da tortura contra os internos (as) é uma realidade denunciada pelos organismos de direitos humanos nacionais e internacionais, as regras de convivência entre os prisioneiros são marcadas por relações de poder baseadas no currículo de crimes, as condutas são marcadas pelos códigos de honra dos prisioneiros. $\mathrm{O}$ rompimento das regras estabelecidas é punido de forma violenta, com vingança, comportamentos de humilhação e poder que podem ir do trabalho forçado, da violência física e sexual até o homicídio de prisioneiros, familiares e outros agentes externos. A Lei da cadeia é implacável!

É neste tipo de ambiente, dominado pela tensão da segurança pública que reconhece que estes espaços podem explodir em fugas, motins e rebeliões a qualquer momento, ou pelo medo e temor gerado pela cultura carcerária que atua o professor. Na maioria das vezes com uma boa formação nas teorias pedagógicas, em Educação popular, mas na maioria das vezes sem conhecer como funciona a prisão: Desconhecem o funcionamento dos comandos, sabem da existência de chaveiros e pouco sobre seu papel na segurança interna, dos chefes de cela, da pena de morte que pode ser decretada de dentro para fora do espaço prisional.

$\mathrm{Na}$ maioria das vezes, os educadores desconhecem os direitos dos presidiários, não tiveram acesso aos documentos internacionais e nacionais que estabelecem tais direitos, realizam uma transposição didática da prática pedagógica das turmas de EJA do sistema de ensino formal para as unidades prisionais. A formação destes educadores negligencia 0 fato de que os mesmos atuam em um ambiente de segurança pública e que a educação no sistema penitenciário está para além da escolarização: Ela tem a função de escolarização e de ressocialização.

\section{Educação específica e diferenciada por quê?}

O ponto de partida para compreender como a Educação foi pensada para o sistema penitenciário deve levar em consideração os pontos trazidos pela LEP de 1984, A Lei de Execução Penal, apesar de ser um documento que data de um ano antes da redemocratização do Brasil, está muito longe de ser vivenciado pelo sistema penitenciário brasileiro. É avançado em muitos sentidos, mas muito limitado quando trata da pessoa privada de liberdade. Seus eixos de ressocialização são: Educação, trabalho e assistência ao condenado. No que diz respeito à educação ela se sustenta na remissão da pena, na educação tecnicista tendo como foco o trabalho, ou educação para o trabalho e a ocupação do tempo da pessoa reclusa. Por ser um documento mais jurídico que pedagógico não há preocupação como a forma, com os 
conteúdos, com os processos de aprendizagem, ou com a formação dos professores.

Educação na prisão significou a partir daí ter um professor alfabetizando réus analfabetos que seguiam para a sala de aula pensando em remir a sua pena. Não havia outro sentido, equipe pedagógica, multiprofissional, formação específica. Muitos professores eram encaminhados para cadeias e prisões como perseguição política ou mesmo não serviam para ensinar nas escolas, ou atender nas bibliotecas, então eram jogados sem formação específica ou qualquer preparação emocional para salas de aulas. Se sentiam com medo, pouco faziam além de ensinar a ler e contar.

Mesmo na atualidade, encontramos muitos desses processos de formação com técnicos que trabalham na EJA, que organizam as chamadas "formações" ou "capacitação" de professores, compreendendo que aos professores das unidades prisionais basta conhecer uma metodologia avançada, a exemplo do método Paulo Freire, ou a teoria construtivista e farão revoluções em suas salas de aulas. Esquecem por exemplo o lugar secundário e sem importância com o qual a escola e os educadores são tratados dentro da prisão: a prioridade é a segurança, educadores estão ali muito mais para atender aos princípios constitucionais, os tratados internacionais do que de fato oferecer uma educação numa perspectiva emancipatória que contribua numa possibilidade de construção de sentido para a vida do recluso.

O problema da educação que envolve seres humanos privados de liberdade não é apenas um problema pedagógico, é um problema pedagógico e de segurança pública. Oe educadores na prisão são prestadores de serviço a segurança pública na medida em que o seu trabalho repercute sobre a forma de pensar e agir do preso. No que tange ao processo de ressocialização, os educadores são parte dessa engrenagem, por mais que o Estado, a polícia, os agentes penitenciários e até a gestão prisional negligenciam a presença dos educadores nos espaços prisionais. Se a segurança pública atua a partir de políticas de repressão e prevenção, no ambiente prisional a escola ajuda no disciplinamento do prisioneiro: cuidar do seu material, tomar banho para assistir aula, usar a roupa adequada, chegar no horário, falar com respeito com os educadores e colegas de sala de aula, um processo de socialização da vida em comunidade que muitas vezes este sujeito de direitos só conheceu dentro da prisão.

Mas é preciso também compreender outra questão, o ambiente da prisão é um ambiente de disputa de poder, o Estado tem poder que se visibiliza através da gestão, dos policiais, dos agentes penitenciários e se revela na capacidade de impor sua vontade, seja pela lei ou pela truculência no tratamento com os reclusos, no poder de ter a pessoa do detento sob sua tutela. Os presos também têm poder que expressam na construção das regras que constrói a cultura do cárcere, os motins, rebeliões, fugas, no crime que se materializa dentro e fora das prisões. E qual é o poder da escola? Qual o poder 
do professor? Entrar quietinho, caladinho, obediente e sair do mesmo jeito da prisão. Ele: o educador (a), atrapalham a rotina, colocam a segurança em risco, quem ouve sua proposta pedagógica? Participam das reuniões que debatem estratégias de segurança pública. Não tem visibilidade, atuam em um ambiente de alto risco, estão submetidos a uma imensa tensão emocional, subjugados a uma hierarquia de caráter militarista que desrespeita os saberes dos educadores que passam a não ter nenhuma função na política pública, estando dentro dela.

Os educadores não participam das reuniões dos grandes pactos de combate violência, de gestão prisional, de política de cuida de gerenciamento de crises e conflitos sabem por qual razão? Estamos vivendo um Estado Penal, a prisão virou regra, perdeu-se a crença na recuperação dos condenados, a cidadão comum clama por mais prisões, por pena de morte por assistir a impunidade crescer por um lado e a corrupção corroer o país por outra. As bandeiras de defesa de direitos humanos desses sujeitos passam a sofrer violentas críticas, discursos nas redes sociais e demais mídias populares associam direitos humanos aos "direitos dos bandidos", educar no ambiente prisional, é muito mais que educar em uma sala de aula de qualquer outro espaço, de trabalho com um sujeito de direito que é rejeitado socialmente. A opinião pública é totalmente desfavorável a recuperação dos prisioneiros, há uma mentalidade exterminadora se desenvolvendo nos últimos anos em relação a eles.

É necessário que a formação dos profissionais de segurança pública e a formação de professores para atuar em espaços de segurança pública, possibilitem um encontro em que policiais, agentes penitenciários, gestores prisionais e educadores se percebem na intersecção que os aproximam: todos atuam em espaços de segurança pública, na relação com sujeitos de direitos na perspectiva de repressão e ressocialização: há uma intersecção que necessita ser considerada.

O professor é exposto a muitos riscos que são negligenciados em sua formação: ao desconhecer o funcionamento da cultura carcerária podem incorrer em situações que coloquem a segurança da unidade prisional em situação de vulnerabilidade: Levar informações, envolvimentos afetivos: de amizade e na perspectiva da sexualidade também. Os profissionais da segurança pública em suas formações são alertados para as estratégias que podem ser construídas pelos reclusos através de linguagens e simbologias que possibilitam o contato com o mundo lá fora. Ao entrar em contato com a família do preso, se relacionar afetivamente e amorosamente o educador pode ultrapassar os limites, assumido condutas que podem inseri-lo no mundo do crime, o que o que organizado sabe fazer com destreza, ou mesmo atuar como assistente social, quando deveria passar estas demandas para os demais profissionais na cadeia. 
É necessário que fique claro para o Estado e para os educadores que as unidades necessitam compreender que o ambiente deve ser tratado como um ambiente de equipe multiprofissional, com funções distintas, mas cada uma delas tem um papel relevante para o processo de ressocialização. A relação hierárquica predominante, submete, humilha e desconsidera o caráter de prevenção que realizam os educadores no ambiente prisional, e perdem a grande possibilidade de traçar estratégias que possam qualificar o trabalho de todos: os que trabalham na segurança e os que atuam na esfera da ressocialização.

\section{Considerações finais}

Em nosso estudo constatamos as contradições e as limitações da educação de pessoas privadas de liberdade no Brasil que tem na discussão pedagógica e política sua estrutura basilar. Inúmeros desafios perpassam tal questão, resultando, assim, numa educação insatisfatória e de baixa qualidade para os/as educandos/as desse complexo sistema, consequências de um Estado neoliberal que vê no Estado apenas uma instância reguladora e nãointerventora das demandas sociais.

A educação penitenciária no Brasil apresenta um papel secundário, sobretudo se a compararmos com a educação regular brasileira. É bastante perceptível sua coadjuvância perante os demais órgãos do Estado responsáveis pela educação no Brasil e sabemos que a educação regular básica ainda padece de melhorias no que diz respeito à qualidade de oferta. $\mathrm{A}$ educação penitenciária não é preocupação das mídias sociais que tem no sensacionalismo e no comércio seu principal instrumento de interesse e lucro, invisibilizando, desta forma, tal questão frente à população geral.

Tal temática apresenta outro desafio: A educação nas prisões não coincide com as políticas de segurança pública. As penitenciárias são subordinadas e coordenadas pelo Ministério da Justiça que organizam através dos governos estaduais que por sua vez organizam as escolas nos espaços de provação de liberdade, a remissão da pena se constitui no principal motor de estimular a pessoa privada de liberdade de estar em sala de aula. Os educadores pouco atuam nas unidades prisionais, suas atividades são secundarizadas. Deste modo, a educação de pessoas privadas de liberdade fica num limiar fronteiriço entre justiça e educação, a qual resulta num complexo objetivo do Estado: o preso deve ser (re) educado ou duramente punido pelo seu crime? Quais ideologias perpassam e se confrontam entre justiça e educação, pois sabemos o quanto aquela é carregada de ideologias burguesas, neoliberais e conservadoras, enquanto esta, se apresenta mais progressista, popular e libertadora. Dessa forma, essa contradição entre educar, ressocializar e punir é o grande desafio para pensar a formação do educador e de um modelo de currículo específico para a educação nas unidades prisionais. 
Nesse contexto, este trabalho não tem como finalidade central propor respostas prontas e acabadas para uma questão tão complexa como esta, pelo contrário, pretende provocar e levar à tona reflexões e discussões na perspectiva de trazer à academia visibilidade para uma temática que tem que ser enfrentada pelos educadores na democratização das relações de poder nas prisões. A sociedade não é algo que acontece à nossa revelia, ao nosso alheamento. Somos sociedade e construtores de um (con) viver melhor e o tratamento e condução do preso também nos diz respeito, caso queiramos um mundo mais humano, democrático, solidário e sem exclusões.

É necessário compreender que pensar na construção de uma sociedade democrática, na construção de uma cultura de paz, no combate a violência e a invisibilidade social dos "miseráveis", teremos de ter uma proposta de intervenção nos ambientes prisionais. O criminoso comum que ainda não foi recrutado pelo crime organizado se ressocializa se até ele, chegam as políticas públicas antes do mundo do crime. Precisamos questionar qual será o papel da educação nesse resgate do homem e da mulher prisioneira numa educação baseada em valores?

\section{Referências}

BARROS, Ana Maria de. JORDÃO, Maria Perpétua Socorro Dantas. A Cidadania e o Sistema penitenciário Brasileiro. VERESAS - Favip. V.1, n. 01, p. 8-17, 2004.

BARROS, Ana Maria de. A Educação Penitenciária em Questão: Notas Para Uma Metodologia. SABERES - Revista do Observatório dos Movimentos Sociais, v. 02, p. 103-120, 2009.

BATISTA, Nilo. Todo Crime é Político. Revista Caros amigos: Ano VII, N.77, agosto, 2003.

BRASIL. Constituição da República Federativa do Brasil. Brasília: Imprensa Oficial, 1988.

BRASIL. Ministério da educação. Lei de Diretrizes e Bases da Educação Nacional. LDB. 9.394, de 20 de dezembro de 1996.

BRASIL. Lei de Execução Penal. LEP. 7.210, de 11 de julho de 1984.

BRASIL. Declaração dos Direitos Humanos da ONU.1948.

COSTA, Edijane da Silva Costa. FARIAS, Érika Fabiana Guimarães. Formação de Professores Profissionais: Perspectivas e Vicissitudes da Formação em Serviço. Revista Espaço Acadêmico, n. 93, fevereiro de 2009.

FOUCAULT, Michel. Vigiar e Punir: Nascimento da Prisão. Petropólis: Vozes, 1987. GOMES, Luziêt Maria Fontene. CÂMARA, Heleusa Figueira. A Educação de Jovens e Adultos no Sistema Prisional: Itinerários de Inclusão. In: I Congresso Internacional da Cátedra Unesco de Educação de Jovens e Adultos. Paraiba: João Pessoa: Editora Universitária da UFPE, 2010.

LUCENA, Helen Halinne Rodrigues de. Egressas Do Sistema Carcerário: processos de aprendizagem ao longo da vida e a luta por reconhecimento. In: CONGRESSO DA CÁTEDRA UNESCO DE EDUCAÇÃO DE JOVENS E ADULTOS, 1, 2010. João Pessoa. Anais do I CONGRESSO INTERNACIONAL DA CÁTEDRA UNESCO DE 
EDUCAÇÃO DE JOVENS E ADULTOS. João Pessoa - PB. Editora Universitária UFPB. Julho - 2010.

MARI, Cezar Luiz de. O Papel Educador dos Intelectuais na Formação Ideológica e Hegemônica em Gramsci: uma perspectiva de emancipação humana. In: 26 Reunião da ANPED, 2003, Poços de Caldas. Novo Governo novas políticas? Rio de Janeiro: Autores Associados, 2003. v. 01.

MATTEUCCI, N. Direitos Humanos. In: Dicionário de Política. BOBBIO, Norberto. MATTEUCI, N. PASQUINO, G. 4. Ed. V. 1. Brasília: EDUnB, 1992.

OLIVEIRA, Romualdo Portela de. O Direito à Educação na Constituição Federal de 1988 e seu Restabelecimento pelo Sistema de Justiça. Revista Brasileira de Educação, v. 1, n. 11, Mai-Ago, 1999.

PORTUGUES, Manoel Rodrigues. Educação de Adultos Presos. Educação e Pesquisa, v. 27, n. 2, p.355-372. Jul/dez, 2001.

SEMERARO, Giovanni. Intelectuais orgânicos, atualidade e contraponto. In: 29a ANPED, 2006, Caxambu. Educação, cultura e conhecimento na contemporaneidade: desafios e compromissos. Rio de Janeiro: ANPED, 2006. V. 1.

SILVA, Maria da Conceição Valença da. A Prática Docente de EJA: O Caso da Penitenciária Juiz Plácido de Souza em Caruaru. Recife: PE. Bagaço, 2006.

SOARES, Maria Victoria Benevides. Cidadania e Direitos Humanos. In: Educação, Cidadania e Direitos Humanos. CARVALHO, José Sérgio (org.). Petrópolis, Rio de Janeiro: Vozes, 2004. 